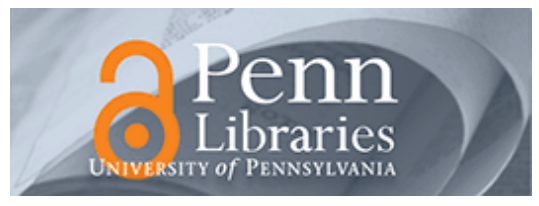

University of Pennsylvania

ScholarlyCommons

Marketing Papers

Wharton Faculty Research

September 1983

\title{
The Importance of Objectivity and Falsification in Management Science
}

\section{J. Scott Armstrong}

University of Pennsylvania, armstrong@wharton.upenn.edu

Follow this and additional works at: https://repository.upenn.edu/marketing_papers

\section{Recommended Citation}

Armstrong, J. S. (1983). The Importance of Objectivity and Falsification in Management Science.

Retrieved from https://repository.upenn.edu/marketing_papers/111

Postprint version. Published in Journal of Management, Volume 9, Issue 3, September 1983, pages $213-216$.

Publisher URL: http://dx.doi.org/10.1177/014920638300900212

This paper is posted at ScholarlyCommons. https://repository.upenn.edu/marketing_papers/111

For more information, please contact repository@pobox.upenn.edu. 


\title{
The Importance of Objectivity and Falsification in Management Science
}

\begin{abstract}
In general, I thought that the Boal and Willis "Note on the Armstrong/Mitroff Debate" provided an interesting and fair discussion. The summary of the consequences of the subjective versus objective approaches (Table 1 in their paper) was helpful. It clearly outlined the dilemma faced by scientists: "Should I strive for personal gain or for scientific contributions?" It also described what is likely to happen to the theories generated from the subjective and objective approaches. For example, the authors claimed that the subjective approach will yield a fuller hearing for a theory.

Given my preference for empirical evidence, I was disappointed that Boal and Willis had little evidence to report. Fortunately, recent research has been done on the above topics. This research supports some of Boal and Willis's conclusions, but it falsifies their conclusion that the subjective approach will provide a fuller hearing for theories.

The evidence seems consistent with Boal and Willis's summary of the conflict between the advancement of scientists and scientific advancement. My summary of the empirical evidence on this conflict led to the "Author's Formula" (Armstrong, 1982a, p. 197). This states that scientists who are interested in career advancement should: (a) not select an important problem, (b) not challenge existing beliefs, (c) not obtain surprising results, (d) not use simple methods, (e) not provide full disclosure, and (f) not write clearly. These rules for scientists conflict with the aims of science. Unfortunately, many scientists use these rules and profit from them. Those who break the rules are often dealt with harshly by the scientific community.
\end{abstract}

\section{Comments}

Postprint version. Published in Journal of Management, Volume 9, Issue 3, September 1983, pages 213-216.

Publisher URL: http://dx.doi.org/10.1177/014920638300900212 
Published in Journal of Management, 9 (1983), 213-216.

\title{
The Importance of Objectivity and Falsification in Management Science
}

\author{
J. Scott Armstrong \\ The Wharton School, University of Pennsylvania
}

\begin{abstract}
In general, I thought that the Boal and Willis "Note on the Armstrong/Mitroff Debate" 1 provided an interesting and fair discussion. ${ }^{2}$ The summary of the consequences of the subjective versus objective approaches (Table 1 in their paper) was helpful. It clearly outlined the dilemma faced by scientists: "Should I strive for personal gain or for scientific contributions?" It also described what is likely to happen to the theories generated from the subjective and objective approaches. For example, the authors claimed that the subjective approach will yield a fuller hearing for a theory.
\end{abstract}

Given my preference for empirical evidence, I was disappointed that Boal and Willis had little evidence to report. Fortunately, recent research has been done on the above topics. This research supports some of Boal and Willis's conclusions, but it falsifies their conclusion that the subjective approach will provide a fuller hearing for theories.

The evidence seems consistent with Boal and Willis's summary of the conflict between the advancement of scientists and scientific advancement. My summary of the empirical evidence on this conflict led to the "Author's Formula" (Armstrong, 1982a, p. 197). This states that scientists who are interested in career advancement should: (a) not select an important problem, (b) not challenge existing beliefs, (c) not obtain surprising results, (d) not use simple methods, (e) not provide full disclosure, and (f) not write clearly. These rules for scientists conflict with the aims of science. Unfortunately, many scientists use these rules and profit from them. Those who break the rules are often dealt with harshly by the scientific community.

\section{Objectivity versus Subjectivity}

While many arguments have been presented on the value of subjectivity in science, little evidence exists to favor such an approach. My original review of the empirical evidence (Armstrong, 1979) led me to conclude that procedures used by many scientists are too subjective.

Cotton (1982) suggests that it is important to distinguish between the conduct of the research work and the reporting of this research. He favors objectivity in reporting. ${ }^{3}$ In my review of the empirical evidence on the communication of scientific research (Armstrong, 1982b), I concluded that objectivity was lacking here also. For example, acceptance of papers is influenced by the institutional affiliation of the author (Peters \& Ceci, 1982). Thus, I do not agree with Boal and Willis that the subjective approach will help theories to get a full hearing. My conclusion is that some theories will get a full hearing: namely, those theories by well-known scientists that confirm popular beliefs. Theories that challenge these beliefs will have more difficulty, especially if by unknown scientists.

Sound research, conducted in an objective manner, often does yield conclusions. In my opinion, evidence on which of several approaches is most useful provides the best way to communicate the results. Furthermore, I see much benefit in scientists becoming enthusiastic about their conclusions and trying to communicate them to large audiences.

\footnotetext{
${ }^{1}$ This paper is submitted as a reply to that note, which appeared in the Journal of Management, 9 (2).

${ }^{2}$ One exception is that the statement on page 204 suggesting concern for objectivity (reconstructed logic) can be justified if it can be shown that only (emphasis added) reconstructed logic is useful in the development of scientific theories. I believe this statement to be fallacious.

${ }^{3}$ Cotton favored subjectivity (advocacy) in conducting research, but he presented no evidence on this.
} 
The concern over shortcomings in objectivity has led to changes in scientific journals. These include formalizing the editorial policies related to objectivity (e.g., calls for papers that test a number of competing and reasonable hypotheses), preparing structured reviewing forms, asking authors to nominate a list of potential referees, and blind reviewing. These appear to be useful steps.

\section{Falsification}

Science requires a combination of confirmation and falsification. Boal and Willis provide a good listing of reasons why falsification might be misleading, though they might also have included errors and cheating. Still, I believe that there is too little emphasis on falsification in management science.

Studies that falsify beliefs are apparently regarded as more useful by scientists. First, falsification studies apparently seem more important to their authors: Greenwald (1975) found that about half of those researchers who falsified the null hypothesis submitted a report for publication, while only $6 \%$ of those who failed to reject the null hypothesis attempted to publish. Reviewers also prefer falsification: The bogus paper in the study by Atkinson, Furlong, and Wampold (1982) was more likely to be accepted for publication when the rejection of the null hypothesis was statistically significant. Finally, other scientists also seem to regard falsification as more important: Christensen-Szalanski and Beach (1984) found that studies showing human judgment to be faulty were cited six times more often than studies showing good performance by judges. Studies confirming current judgmental procedures do not call for changes. Those that show current judgmental procedures to be wrong should receive more attention, not only for further testing, but also to determine better ways to make judgments.

Unfortunately, falsification is often misused in order to protect existing beliefs. For example, a scientist can create the illusion of falsification by using a widely held existing belief as the proposed hypothesis, with a trivial alternative as the null hypothesis. The trappings of science, such as mathematics and obscure writing, are then used to enhance the proposed hypothesis. The defeat of the null hypothesis is used to support the existing belief. My guess is that such a study will mislead scientists by adding to their confidence in this belief.

The scientist must keep in mind that falsification of important beliefs is dangerous work. Mahoney's (1977) experimental study shows that other academicians will claim that the quality of the research is poor. (If you don't believe experimental studies, it can be learned by experience: Just try to publish such a study.) Manwell (1979) reports that he nearly lost his position as a tenured professor by challenging existing dogma. Threats were made to Peters and Ceci as a result of their quasi-experimental study suggesting that existing journal review procedures are faulty (Sieber, 1983).

Some journals are trying to encourage the publication of papers that falsify existing important beliefs. One approach is to reserve space for the publication (without review) of highly controversial studies. Another approach is to publish controversial studies along with commentary (Harnad, 1979). Still another approach is to publish the referees' reports (with the agreement of the referees) for controversial papers. Finally, publication prospects for controversial papers might be improved by asking referees to evaluate the study when the results are withheld. (This procedure is used, when requested, by the Journal of Forecasting.) All of these steps seem to be useful in dealing with studies falsifying important beliefs.

\section{Conclusions}

Arguments on the best way to do research should be subjected to empirical research. Much has already been learned from recent research. My conclusion from this research is that those who call for more subjectivity in scientific research or reporting are looking at a major shortcoming in scientific practice and are proclaiming it to be a virtue. 


\section{References}

Armstrong, J. S. (1979), “Advocacy and objectivity in science,” Management Science, 25, 423-428.

Armstrong, J. S. (1982a), "Barriers to scientific contributions: The author's formula," Behavioral and Brain Science, $5,197-199$.

Armstrong. J. S. (1982b), "Research on scientific journals: Implications for editors and authors," Journal of Forecasting, 1, 83-104.

Atkisson, D. R., Furlong, M. J., \& Wampold, B. B. (1982), "Statistical significance, reviewer evaluations, and the scientific process: Is there a statistically significant relationship?” Journal of Counseling Psychology, 29, 189-194.

Chrislensen-Sralmeki, J. J., \& Beach, L. R. (1984), "The citation bias: Fad and fashion in the judgment and decision literature," American Psychologist, 39, 75-78.

Cotton, J. L. (1982), “Objective versus advocacy models of scientific enterprise: A comment on the Mitroff myth,” Academy of Management Review, 7, 133-135.

Greenwald, A. (1975), “Consequences of prejudices against the null hypothesis,” Psychological Bulletin, 82, 1-20.

Harnad, S. (1979), “Creative disagreement,” The Sciences, 19, 18-20.

Mahoney, M. (1977), "Publication prejudices: An experimental study of confirmatory bias in the peer review system," Cognitive Therapy and Research, 1, 161-175.

Manwcll. C. (1979), "Peer review: A case history from the Australian Research Grants Committee," Search, 10, 81-86.

Peters, D. P., \& Ceci, S. J. (1982), "Peer review practices of psychological journals: The fate of published articles submitted again," Behavioral and Brain Sciences, 5, 187-195.

Sieiber, J. E. (1983), "Whose ethics? Or the perils and ethics of studying powerful persons," Society for the Advancement of Social Psychology Newsletter, 9, 1-5. 